\title{
Improvement of High Temperature Wear Resistance of AISI 316 ASS through NiCrBSiCFe Plasma Spray Coating
}

\author{
N. L .Parthasarathi, Muthukannan Duraiselvam*
}

Department of Production Engineering, National Institute of Technology, Tiruchirappalli-620 015, Tamil Nadu, INDIA

*Corresponding author: durai@nitt.edu

\begin{abstract}
In this work, the microstructural description, mechanical properties and dry sliding wear features of NiCrBSiCFe plasma sprayed on AISI 316 austenitic stainless steel (ASS) substrate were examined. Defect-free metallurgically bonded coatings were obtained. Wear tests were carried out at $2 \mathrm{~m} / \mathrm{s}$ sliding velocity under the load of $20 \mathrm{~N}$ for $2000 \mathrm{~m}$ sliding distance at various conditions like room temperature $\left(35^{\circ} \mathrm{C}\right), 150^{\circ} \mathrm{C}, 250^{\circ} \mathrm{C}$ and $350^{\circ} \mathrm{C}$ using a $\mathrm{EN}-8$ medium carbon steel pin as a counterface material. The properties namely coating density, micro hardness, coefficient of friction ( $\mathrm{CoF}$ ) and wear resistance of the coating were studied. $\mathrm{NiCrBSiCFe} \mathrm{plasma} \mathrm{spray} \mathrm{coated} \mathrm{steel} \mathrm{substrate} \mathrm{showed} \mathrm{superior} \mathrm{wear} \mathrm{resistance} \mathrm{properties}$ than the uncoated steel substrate in all the temperatures. The sliding wear resistance was improved up to 4.5 times than that of the uncoated material. In wear test carried out at $350^{\circ} \mathrm{C}$, the coated substrates showed relatively lesser wear than in other temperatures due to the oxide formation, which acted as a protective layer. In addition, the shallow ploughing mode of wear reduced the severity of material removal at $350^{\circ} \mathrm{C}$. Using scanning electron microscope (SEM) pictures, the wear properties of the coated steel substrate were evaluated in terms of plastic deformation, material transfer and abrasion.
\end{abstract}

Keywords: AISI 316 ASS; NiCrBSiCFe; Plasma spraying; Abrasion; Wear.

\section{INTRODUCTION}

AISI 316 austenitic stainless steel (ASS) is a frequently used engineering material employed in high temperature applications because of its excellent corrosion resistance. Due to the low hardness of the AISI 316 ASS, continual attempts were made to enhance hardness thereby to improve the wear resistance. A detailed study on sliding-wear evaluation of nitrided austenitic alloys was carried out. During the contact with themselves or other materials, ASS 
frequently suffers severe metallic wear, due to the formation of strong adhesion junctions between the contact surfaces [1].

The wear of AISI 316 ASS was studied in a variety of gaseous atmospheres at constant load and sliding speed under reciprocating conditions. The environments such as air, $\mathrm{CO}_{2}$, argon and partial vacuum were investigated. The wear debris in all cases was essentially metallic and its rate of production per unit length was constant with sliding distance [2].

In austenitic and martensitic steels, the load and sliding speed dependencies of the coefficient of friction $(\mathrm{CoF})$ and temperature was studied. It was shown that severe adhesive wear (seizure) conditions result in formation of 20 to $40 \mu \mathrm{m}$ thick layer with the fine-crystalline microstructure [3]. Room temperature tests on air and vacuum plasma-sprayed TiC-NiCrBSi coatings using a pin-on-disc tribometer at various loads and sliding speed have been performed in order to understand the effects of the parameters on the coating wear and friction behaviour. Results have shown that load, sliding speed and the plasma spray process affect the wear resistance and the friction behaviour of thermally sprayed coatings. Higher loads during sliding led to higher wear rates for both air and vacuum plasma sprayed coatings [4]. NiCrAlY and CoNiCrAlY powders were thermal-sprayed using the high frequency pulse detonation method (HFPD) onto AISI 310 ASS samples to obtain dense, adherent, high temperature oxidation resistant coatings.

The oxidation kinetics of both coatings was characterized by parabolic rate constants, which are very close to those for the formation of aluminium oxide on nickel or cobalt based alloys [5]. The plasma carburized layers prevented surface plastic deformation and improved the wear resistance of the steel during the early stages of the wear process. Subsurface plastic deformation occurs beneath the layer, leading to the catastrophic failure of the layer and a transition in the wear rate after a limited duration of testing.

Three carburized layers with varying thickness, ranging from 15 to $40 \mu \mathrm{m}$ were tested and the thickest layer tested produced the best wear performance under the rolling-sliding test conditions. [6]. The dry sliding behaviour of an austenitic stainless steel and a duplex 2205 austenitic-ferritic stainless steel was investigated. The evolution of wear was characterised by the existence of a sliding distance transition. In particular, wear passed from delamination to tribo-oxidation, with a reduction in wear rate [7].

A low temperature plasma carburising technique was developed to engineer the surfaces of austenitic stainless steels to achieve combined improvement in wear and corrosion resistance. The resultant carburised layer was free from carbide precipitates and contained a single austenite phase supersaturated with carbon. The results showed that the hard and corrosion resistant carburised layers are effective in preventing surface plastic deformation, eliminating adhesive and severe abrasive wear [8]. Tribological reactions on the friction and wear of quasicrystalline materials (Al-Ni-Co-Si) and coatings with two alloy compositions have been prepared by plasma and high velocity oxy fuel (HVOF) spraying techniques. The tribolayers were characterised by the formation of a transfer film on the counterface and densification of 
the coating subsurface. The wear rate appeared to be controlled by the thickness of the porefree region formed within the coating surface zone [9].

A modified $\mathrm{NiCr}$ coating was thermal-sprayed using different procedures (flame, plasma, HVOF and HFPD) onto stainless steel specimens. The microstructures, porosities, oxide contents and microhardness of the coatings were determined [10]. Plasma-sprayed nickel coatings on stainless steel and cobalt alloy coupons heated to temperatures ranging from room temperature to $650^{\circ} \mathrm{C}$. Heating the substrate removes surface moisture and other volatile contaminants, delays solidification of droplets, helps to penetrate the surface cavities, and promotes diffusion between the coating and substrate. All these mechanisms enhance coating adhesion [11].

A study on the effect of relative humidity and applied load range on the friction and wear of AISI 304 austenitic stainless steel were characterized by two different grain sizes of 2.5 and $40 \mu \mathrm{m}$. At loads of $2 \mathrm{~N}$, using a standard ball-on-disc tribometer, severe wear was evident at low humidity, while relatively lower wear was observed at high humidity indicating a lubricating effect of water [12]. For the protection of the surfaces against degradation, the HVOF spraying with high strength, hardness, low porosity (less than 1\%), high erosioncorrosion and wear resistances were employed. The role of some HVOF coatings in the protection of metals and alloys against degradation at high temperatures in various media was studied [13]. The effect of localised laser melting of plasma sprayed NiCrBSi coatings, on the corrosion behaviour was investigated. The microstructure of the coatings was analysed by SEM and energy dispersive spectroscopy (EDS) analysis [14]. The plasma spraying technique was used to get the solid lubrication iron sulfide coating on the 1045 steel. The friction test of the FeS coatings, tested on a ring-on-block tester, showed that the plasma spraying FeS coatings possessed the remarkable friction-reduction performance. The worn failure mechanism of the coatings was flaking off [15].

The wear behavior of the coating was evaluated using a pin on disc wear system against $\mathrm{SiC}$ abrasive medium of 120 and 600 grades at 5, 10, 15, and $20 \mathrm{~N}$ normal load. Results revealed that the influence of normal load on wear is governed by the microstructure, hardness and abrasive grit size. The heat treatment increased average microhardness of the coating [16].

The effect of nitrogen ion implantation with energy of $125 \mathrm{keV}$ on such tribological characteristics of AISI316L ASS as the friction coefficient, wear resistance, and microhardness was studied. An increase in the abrasion resistance after implantation was detected, which was different for various media. The largest increase in the wear resistance was observed during testing in air. The largest decrease in the CoF was observed for all implanted samples in argon atmosphere [17].

Friction and wear characteristics of $\mathrm{Al}-\mathrm{SiC}$ composites have been investigated under dry sliding conditions and compared with those observed in pure aluminium. Dry sliding wear tests have been carried out using pin-on-disc wear test rate normal loads of 5, 7, 9 and $11 \mathrm{Kgf}$ 
and at constant sliding velocity of $1.0 \mathrm{~m} / \mathrm{s}$. The best results have been obtained at $20 \%$ weight fraction of 320 grit size SiC particles for minimum wear [18].

Glow discharge (GD) nitro carburizing, at low carbon content and different working temperatures, was performed on AISI 316L and AISI 304 stainless steels. At working temperatures higher than $400^{\circ} \mathrm{C}$, roughness increased and wear was limited to asperity compaction. Wear was reduced by up to a factor of 5 in treated steels [19]. NiCrBSi has been deposited onto $0 \mathrm{Cr} 13 \mathrm{Ni5M}$ stainless steel using the activated combustion high velocity air fuel (AC-HVAF) technique. The structure and morphologies of the Ni-based coatings were investigated by XRD, SEM and EDS [20]. In the above studies, the influence of temperature in the tribological properties was not highlighted.

The existing studies did not focus on the working conditions of the sliding wear and the worn tracks of the coatings were not characterised with respect to the temperatures. In this work, the $\mathrm{NiCrBSiCFe}$ was plasma sprayed on AISI 316 ASS and the tribological properties were evaluated at different temperatures such as room temperature $\left(35^{\circ} \mathrm{C}\right), 150^{\circ} \mathrm{C}, 250^{\circ} \mathrm{C}$ and $350^{\circ} \mathrm{C}$ using a pin-on-disc tribometer. The influence of microstructure and hardness of the coating on the wear resistance was explained. The wear mechanism was identified by correlating SEM and XRD analysis.

\section{EXPERIMENTAL PROCEDURE}

\subsection{Materials and Plasma Spraying Process}

The as-received AISI 316 ASS sheets were machined into a disc of $100 \mathrm{~mm}$ diameter and $4 \mathrm{~mm}$ thickness. Acetone was used for degreasing. The substrates were grit blasted to improve the surface roughness to a $\mathrm{R}_{\mathrm{a}}$ value of $10 \mu \mathrm{m}$. Micro- Melt ${ }^{\mathrm{B}} \mathrm{B}-60 \mathrm{NiCrBSiCFe}$ alloy powder supplied by Carpenter Powder Products Inc., U.S.A. was used as a raw material. The morphology of NiCrBSiCFe powder particles was analysed by SEM. The powder consists of gas atomised spherically shaped particle as is shown in Figure 1. The mean particle size of the feedstock powder used in the present study was identified as $63.72 \mu \mathrm{m}$. An EN-8 medium carbon steel pin was used as a counterface material. The chemical composition of substrate, powder and counterbody is shown in Table 1. During plasma spraying, the spray gun (Sulzer Metco SST-24) was stationary and the specimen was mounted on a rotating table. The coating feedstock material was injected vertically into the plasma jet by argon (Ar) carrier gas for primary flow and hydrogen gas $\left(\mathrm{H}_{2}\right)$ for secondary flow. The plasma coating was performed up to $500 \mu \mathrm{m}$ thickness. The selected spray parameters are given in Table 2. 


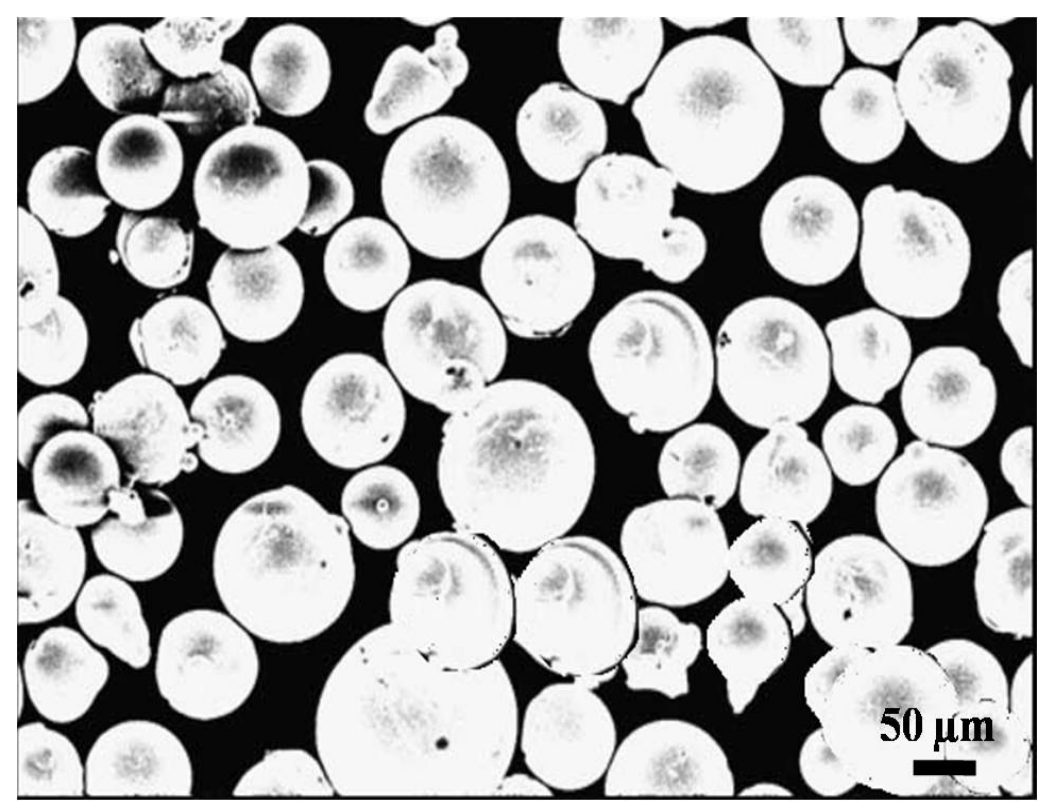

Figure 1. SEM morphology of NiCrBSiCFe powder

Table 1. Chemical composition (wt. \%) of spray powders and the counterbody

\begin{tabular}{lcccccccccc}
\hline Elements & Ni & Cr & B & Si & C & Fe & S & Mn & Mo & P \\
\hline $\begin{array}{l}\text { AISI 316 } \\
\begin{array}{l}\text { Substrate } \\
\text { NiCrBSiCFe } \\
\text { Powder }\end{array}\end{array}$ & 14 & 18 & -- & 1.0 & 0.08 & Bal. & 0.03 & 2.00 & 3.00 & 0.045 \\
$\begin{array}{l}\text { EN-8 } \\
\text { counterbody }\end{array}$ & -- & 13.3 & 3.1 & 3.9 & 0.5 & 3.7 & -- & -- & -- & -- \\
\hline
\end{tabular}

Table 2. Selected Processing Parameters.

\begin{tabular}{|c|c|}
\hline Spray parameter & Value \\
\hline Substrate & AISI 316 ASS \\
\hline D.C. Current (A) & 480 \\
\hline D.C. Volts ( v) & 70 \\
\hline Primary gas flow rate (SLPM) & 150 \\
\hline Hydrogen & 15 \\
\hline Feedstock carrier gas flow rate (SLPM) Argon & 37 \\
\hline Powder flow rate (g/min) & 120 \\
\hline Stand-off spray distance $(\mathrm{mm})$ & 125 \\
\hline Scanning velocity $(\mathrm{mm} / \mathrm{sec})$ & 6 \\
\hline Coating thickness $(\mu \mathrm{m})$ & 500 \\
\hline
\end{tabular}




\subsection{Wear Test}

Wear tests were carried out under dry sliding condition on a DUCOM pin-on-disc tribometer, model TR-20-M-106 as shown in Figure 2. The linear variable differential transducer (LVDT) probe was positioned on the weights to measure displacement and the load cell to sense the tangential force. ASTM G99-05 [21], the standard test method for wear testing with a pin-on-disc apparatus was slightly deviated by having plasma sprayed steel disc as a specimen for characterising the coating. The counterface material, EN-8 medium carbon steel, was prepared in the form of pin with a dimension of $31 \mathrm{~mm}$ height and $6 \mathrm{~mm}$ diameter. The pin was made to slide on the coated steel disc at $2.0 \mathrm{~m} / \mathrm{s}$ sliding speed under the load 20 $\mathrm{N}$ for $2000 \mathrm{~m}$ sliding distance.

The NiCrBSiCFe plasma coated samples were polished by surface grinding to attain the surface roughness value $\mathrm{R}_{\mathrm{a}} \sim 1 \mu \mathrm{m}$. The wear tests were conducted at temperatures such as room temperature $\left(35^{\circ} \mathrm{C}\right), 150^{\circ} \mathrm{C}, 250^{\circ} \mathrm{C}$ and $350^{\circ} \mathrm{C}$. Before and after test, the plasma sprayed disc substrates were ultrasonically cleaned, dried and weighed using an electronic analytical balance to an accuracy of $0.1 \mathrm{mg}$. By using the data acquisition system, the depth of wear and the frictional force were recorded automatically with respect to time. Using the mass loss, the volume loss was computed using equation 1 . The wear resistance was calculated using equation 4. The measured frictional force from the data acquisition system was used to compute CoF using equation 5.

Folume $\operatorname{logs}\left(\mathrm{mm}^{2}\right)=\left(\frac{\text { Mar lori }}{\emptyset}\right) \times 1000$

$$
\text { Coating density }(\rho)=\rho_{1} \times\left(\frac{m_{2}}{m_{2}-m_{1}}\right)
$$

Where, $\rho_{1}$ is the density of water $\left(1 \mathrm{~g} / \mathrm{cm}^{3}\right.$ at room temperature $), \mathrm{m}_{\mathrm{a}}$ is the weight of the plasma coating in air $(\mathrm{g})$ and $\mathrm{m}_{1}$ is the weight of plasma coating in water $(\mathrm{g})$. The wear rate and wear resistance was calculated by the following equations:

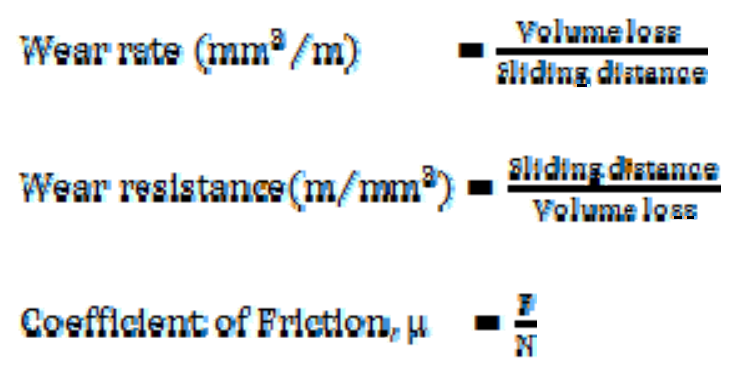

Where, $\mathrm{F}$ is the Frictional force in $\mathrm{N}, \mathrm{N}$ is normal applied load in $\mathrm{N}$. 


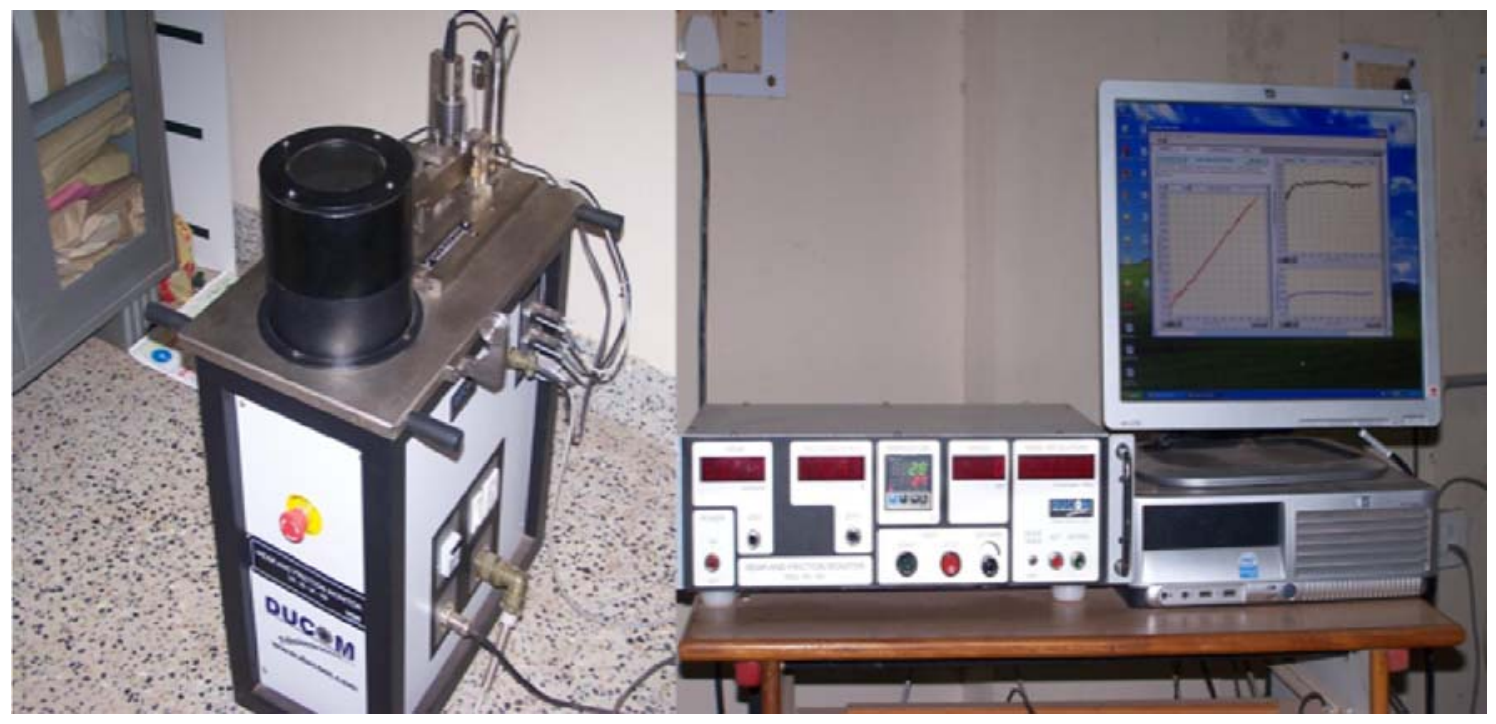

Figure 2. Experimental setup for pin-on disc

\subsection{Coating Characterisation}

The following methods were used to characterise the coatings.

\subsubsection{Microstructural and XRD characterisation}

The plasma sprayed AISI 316 ASS samples were sectioned, polished and etched with Nital. The etched specimens were studied by optical microscopy (OM). The micrograph of EN-8 medium carbon steel was also analysed. The worn tracks of the plasma sprayed specimens were analysed using SEM (HITACHI S $3000 \mathrm{H}$ ) to identify the mode of material loss during sliding at different temperatures. The phase constitution of uncoated and as-sprayed AISI 316 ASS specimens was evaluated by XRD analysis with $\mathrm{CuK}_{\alpha}$ radiation source (D/MAX ULTIMA III, Rigaku Corporation, Japan) operating at $30 \mathrm{~mA}$ and $40 \mathrm{kV}$. The set scanning speed and the scanning range are $2 \% / \mathrm{min}$ and $10-80^{\circ}$, respectively.

\subsubsection{Characterisation of NiCrBSiCFe as-sprayed coated surface}

The concept of splat formation due to the impact of spherical powder on the substrate during plasma spraying is schematically shown in Figure 3(a). The as-sprayed NiCrBSiCFe plasma coated surface is shown in Figure 3(b). The splat formed due to the impact of the molten spherical powder on the substrate was clearly captured by SEM. These splats aided the lamellar microstructure formation, which offered higher hardness and wear resistance. The coated surface when analysed by SEM revealed the presence of small voids. The as-sprayed surface also showed sparsely distributed unmelted spherical particles. These unmelted spherical powder particles were visible due to the high flight in velocity of the particle. 


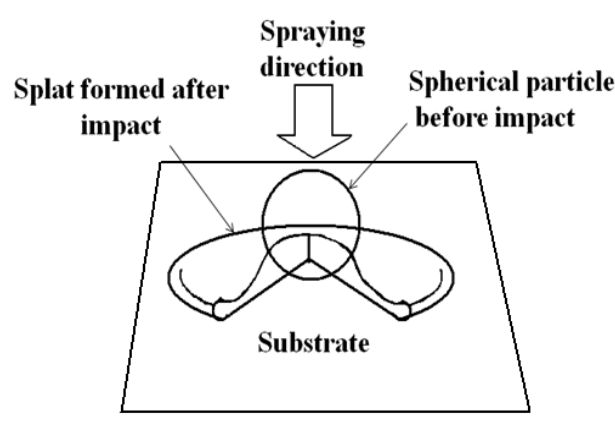

(a)

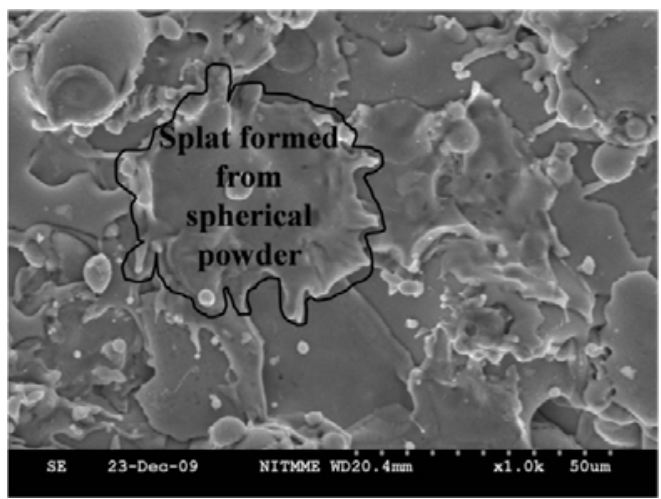

(b)

Figure 3. (a) Splat formation after the impact of the spherical powder during spraying (b) As-sprayed NiCrBSiCFe plasma coated surface

\subsubsection{Microhardness and density measurement}

The microhardness was measured using Zwick MHT Vickers hardness tester at a load of 300 $\mathrm{g}$ for 20 seconds. Using the molecular formula, the theoretical density of the $\mathrm{NiCrBSiCFe}$ plasma sprayed coating was calculated as $8.146 \mathrm{~g} / \mathrm{cm}^{3}$. In order to determine the actual density, the NiCrBSiCFe coating was mechanically peeled off from the substrate and measured using Archimedes principle as per equation 2. The average actual density of the coating was $8.116 \mathrm{~g} / \mathrm{cm}^{3}$.

\section{RESULTS AND DISCUSSIONS}

\subsection{Coating Microstructure}

The cross-sectional microstructures of NiCrBSiCFe plasma sprayed coatings are shown in Figure 4(a) and (b). The improved roughness by grit blasting was explicitly visible as undulations on the interface region aided for a good metallurgical boding. The micrograph indicated that the physical bonding between the coating and the interface was sound. Absence of pores in the interface region substantiated that the bonding was intact. The microstructure of the coatings showed elongated splats (explained in section 3.5) of molten powder forming a lamellar structure. This structure was responsible for the higher hardness, which offered superior wear resistance. The absence of microcracks showed that the processing parameters selected in this study have ensured a good quality of plasma sprayed coatings. The microstructure of the substrate, AISI 316 ASS is shown in Figure 3(c). The austenitic structures were clearly visible. The microstructure of the counterbody, EN-8 medium carbon steel pin is shown in Figure 3(d). The structure was "body-centered tetragonal" (BCT) and 
was classed as a hard ferro-magnetic group. The presence of frequent carbides in the microstructure was responsible for the higher hardness.

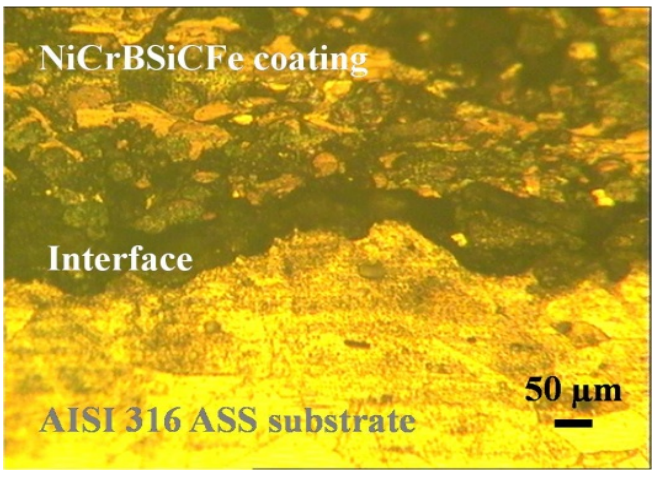

(a)

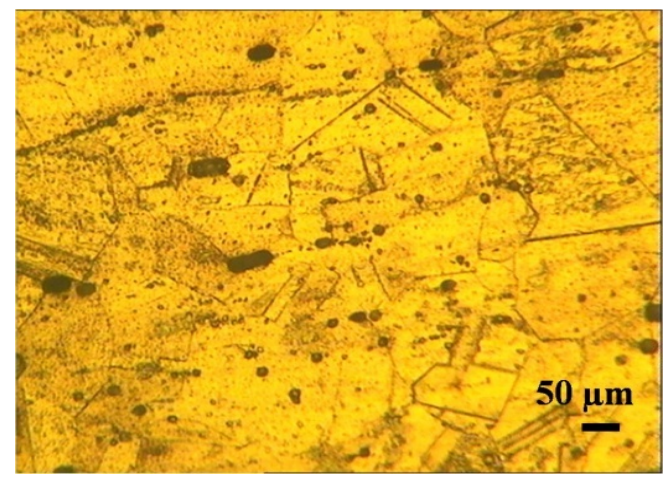

(c)

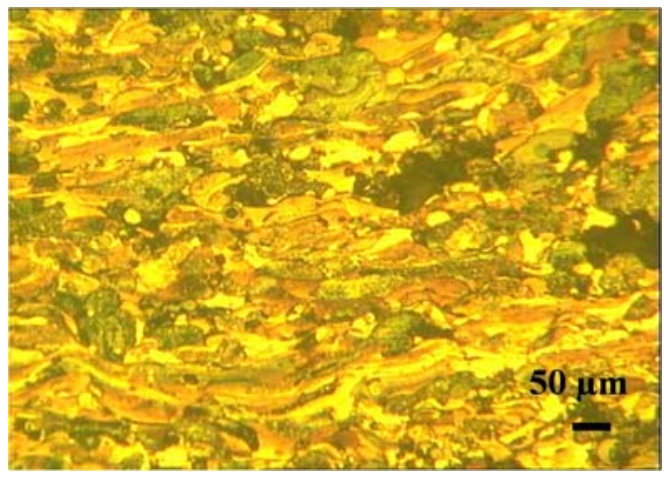

(b)

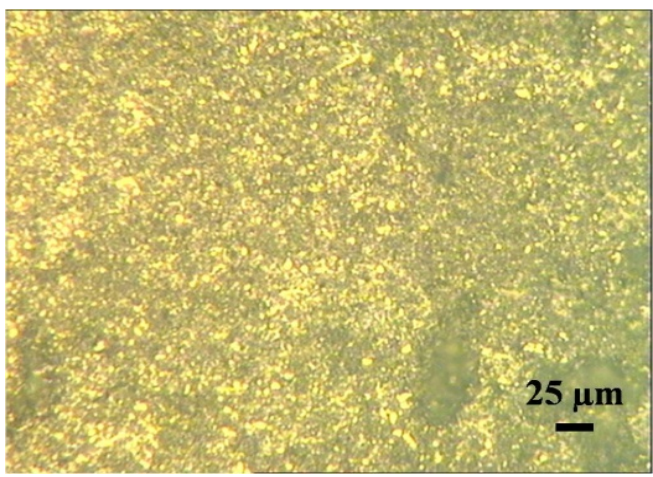

(d)

Figure 4.Cross-sectional micrographs: (a) interface and coating, (b) lamellar structure of the as-sprayed structure of the NiCrBSiCFe plasma sprayed coating, (c) AISI 316 ASS substrate (d) EN-8 medium carbon steel counterbody

\subsection{Microhardness Characterisation}

The Vickers hardness of AISI 316 ASS substrate and EN-8 medium carbon steel pin was 223 $\mathrm{HV}_{0.3}$ and $302 \mathrm{HV}_{0.3}$, respectively. Three distinct regions were distinguished in the hardness profile namely plasma sprayed coating, interface and substrate. The microhardness of the cross section of the NiCrBSiCFe coatings as a function of distance from the coating substrate is shown in Figure 5. The microhardness of the NiCrBSiCFe plasma coating is found to vary with the distance from the coating-substrate interface. Coating microhardness values were found to be in the range of 730-918 $\mathrm{HV}_{0.3}$. The maximum value of about $918 \mathrm{HV}_{0.3}$ was obtained in the top of the coating, which may be the point of the carbide or boride formed during plasma spraying. The average microhardness value is $822 \mathrm{HV}_{0.3}$. The interface region showed an intermediate hardness values ranging 294-398 $\mathrm{HV}_{0.3}$. The increase of hardness of 
AISI 316 ASS substrates due to the plasma sprayed coating was responsible for the superior wear resistance.

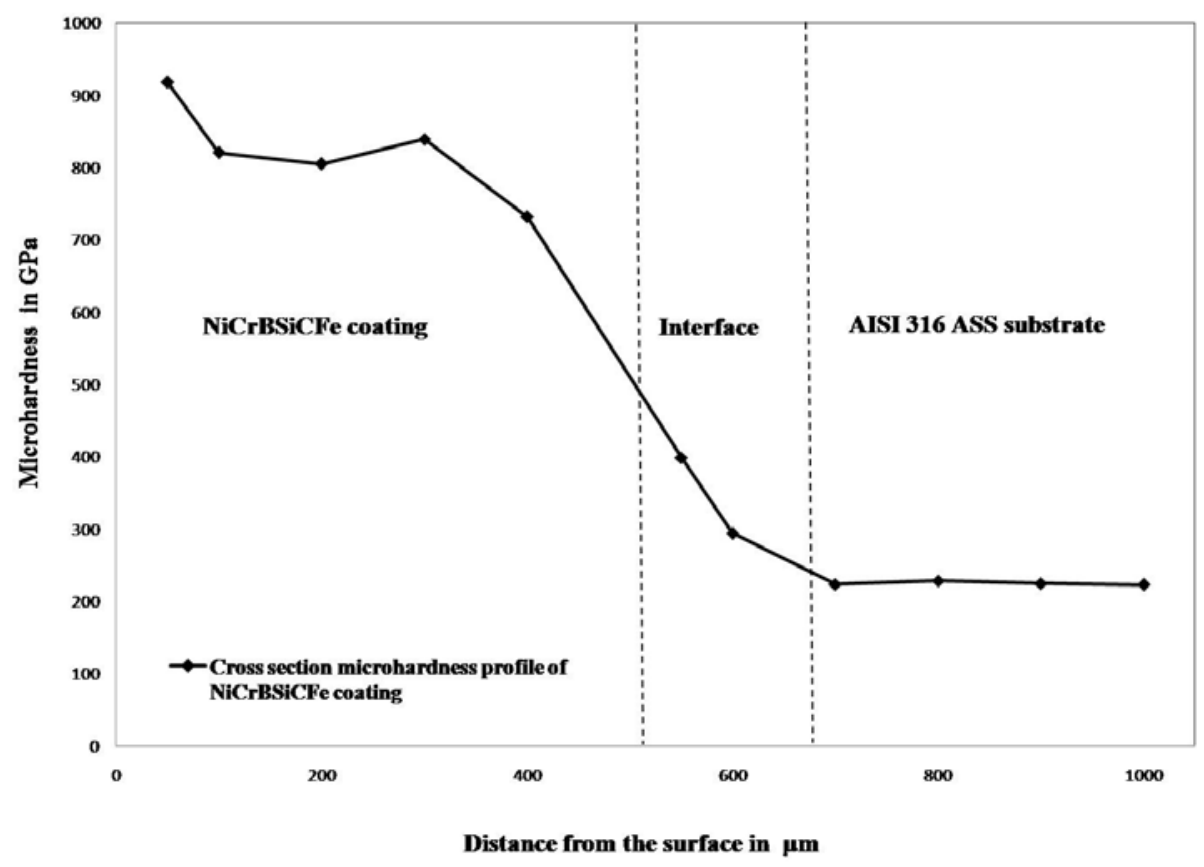

Figure 5. Microhardness variation of the NiCrBSiCFe coatings as a function of the distance from the surface

\subsection{Friction and Wear Behaviour}

The consolidated wear with respect to time at different temperatures is shown in Figure 6. The wear was primarily dominated by plastic deformation. In uncoated AISI 316 ASS substrate, it was inferred that the wear at $250^{\circ} \mathrm{C}$ was higher than that of the rest of the temperatures. The wear rate at $350^{\circ} \mathrm{C}$ was initially found to be higher, but as time proceeds, the oxide layer formations considerably reduced the wear. The hard oxide layers formed might have induced slipping in sliding wear. Except in $350^{\circ} \mathrm{C}$, the uncoated AISI 316 ASS showed severe wear in all operating temperatures. In contrast, the $\mathrm{NiCrBSiCFe}$ coated samples showed very less wear in all temperatures. Relative sliding between the contacting surfaces leads to the rupture of these junctions and subsequent material transfer from one surface to the other, in addition to the production of debris and material loss. The presence of a lubricating oxide film reduces the tendency for adhesive wear occurrence [22].

Notably in $350^{\circ} \mathrm{C}$, the wear rate was marginally lesser than the rest of the temperatures due to the initiation of oxide layers, which was also substantiated by SEM analysis (Figure 10 (d) and $11(\mathrm{~d})$ ). The CoF for the uncoated AISI 316 ASS varies between 0.4 and 0.5 in all the temperatures and is shown in Figure 7. In NiCrBSiCFe coated discs, the CoF was found to be 
relatively lesser and was ranging from 0.2 to 0.4 in all temperatures. In coated samples worn at $350^{\circ} \mathrm{C}$, the $\mathrm{CoF}$ was in the lower optimum range of 0.2 to 0.3 . This optimum value might be due to the oxide formations in the interface at $350^{\circ} \mathrm{C}$. The oxide formations were explained in detail in section 3.6. The wear resistances of the uncoated and plasma sprayed steel substrates are shown in Figure 8. The highest wear resistance of $693.92 \mathrm{~m} / \mathrm{mm}^{3}$ was recorded for the plasma sprayed steel substrate at $350^{\circ} \mathrm{C}$.

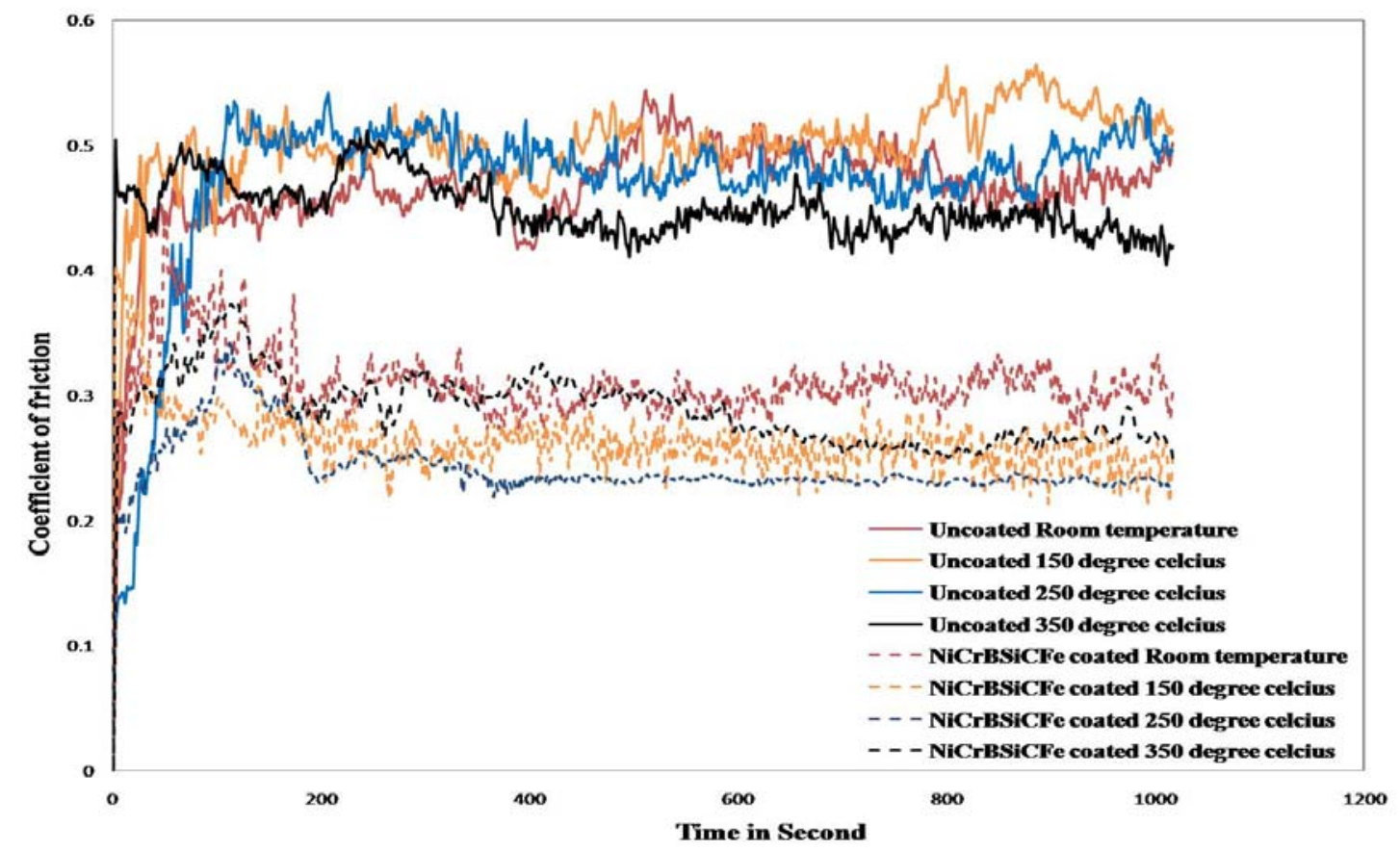

Figure 6. Variation of wear with respect to time and temperature. 


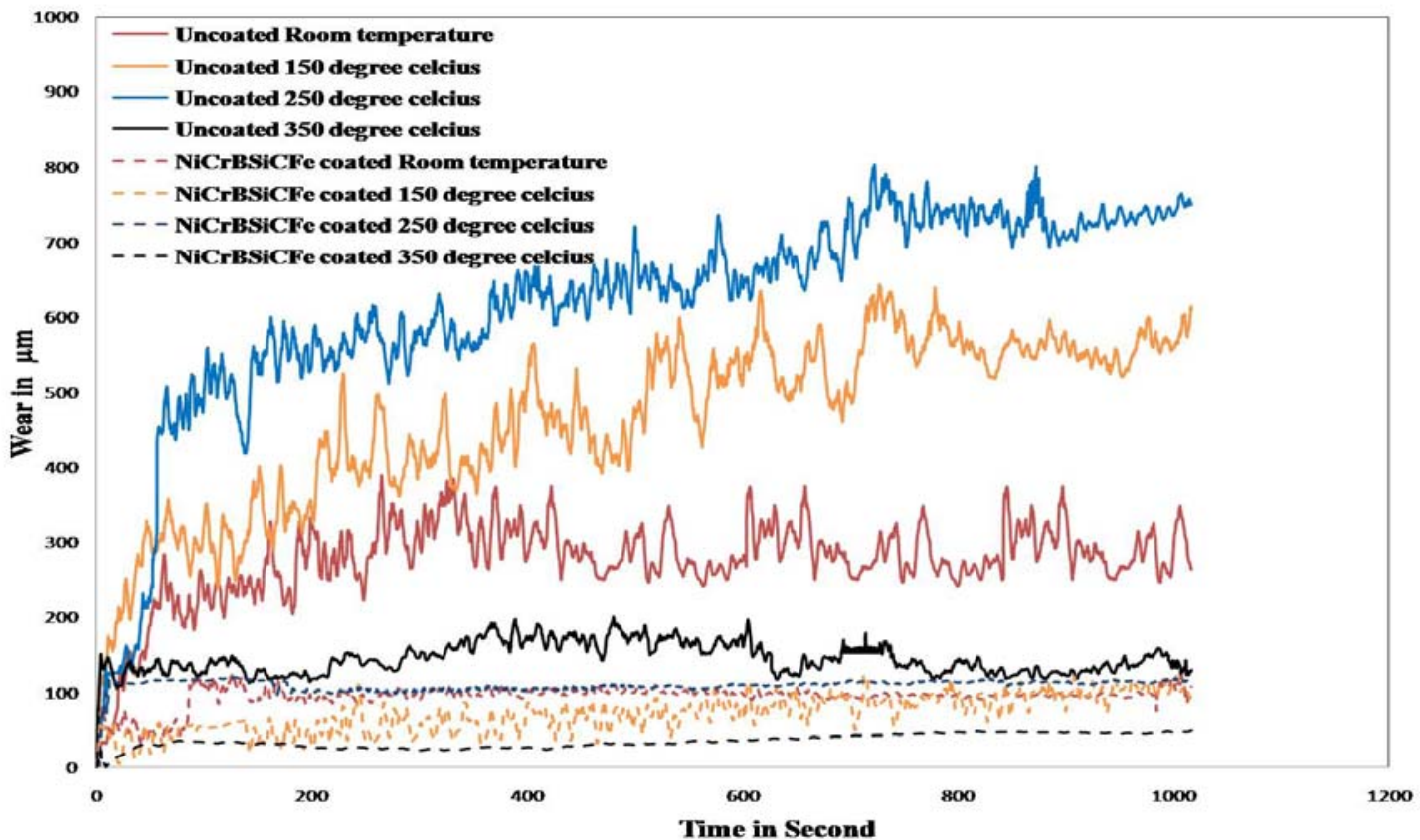

Figure 7. Variation of coefficient of friction with respect to time and temperature

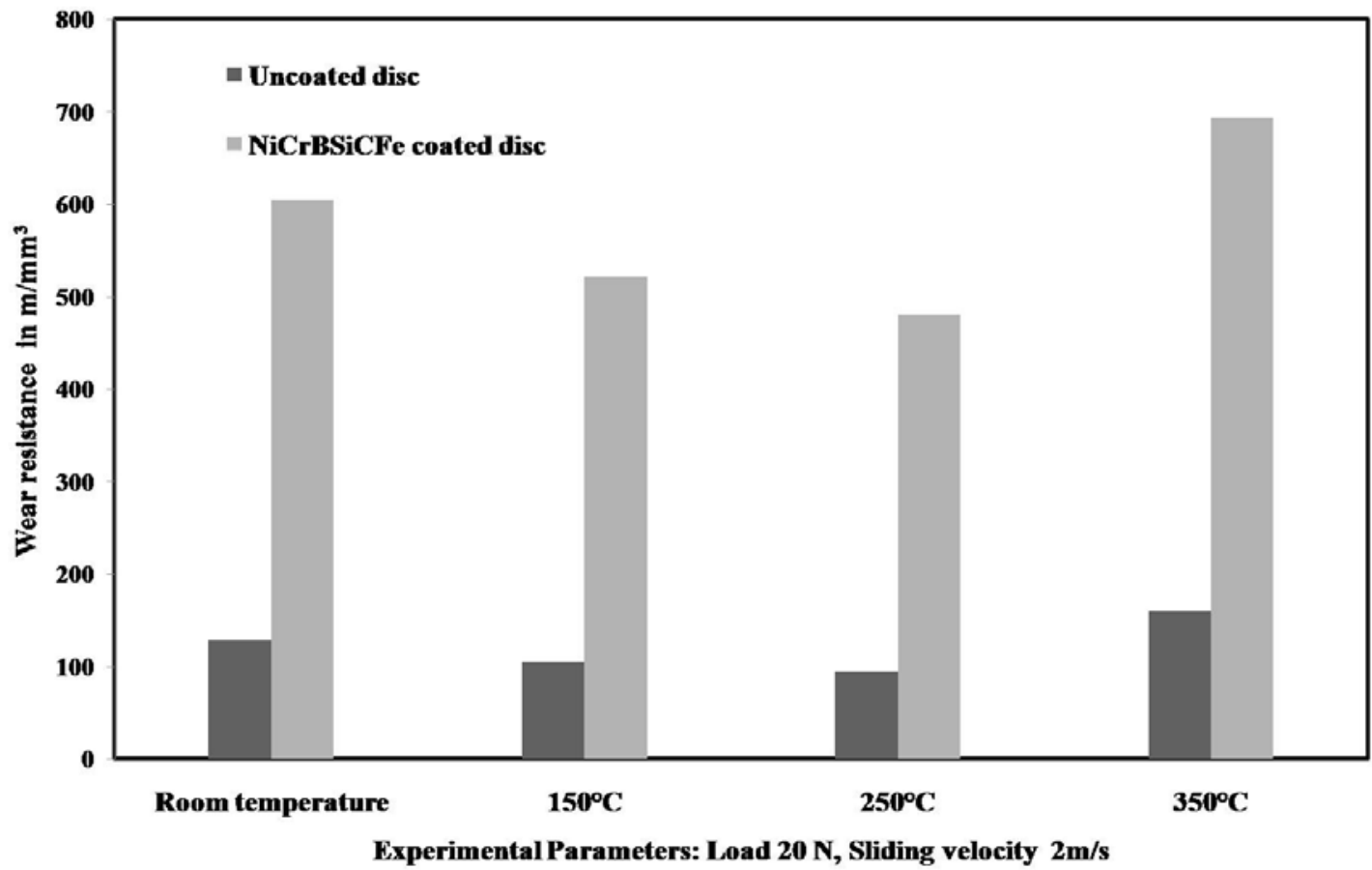

Figure 8. Comparison of wear resistances of uncoated and $\mathrm{NiCrBSiCFe}$ coated samples with respect to temperature 


\subsection{Phase Identification by XRD}

The consolidated XRD patterns of the uncoated and NiCrBSiCFe coated AISI 316 ASS substrates were shown in Figure 9. It reveals the peaks having the phases of $\gamma$-Iron (FCC) in all operating temperatures. The peaks reveal the presence of certain intermetallics namely $\mathrm{Fe}_{3} \mathrm{~B}$ [20], $\mathrm{Cr}_{1.12} \mathrm{Ni}_{2.88}$ and $\mathrm{Ni}_{3} \mathrm{~B}$ [14]. Si and $\mathrm{Cr}$ peaks were also present in smaller intensities. It is also clear that there are no new phases formed in the coating during the thermal spray process. The major intermetallic found in the coated surface was $\mathrm{Cr}_{1.12} \mathrm{Ni}_{2.88}$ in all operating temperatures. The formation of the intermetallics was also responsible for the higher hardness and superior wear resistance in the NiCrBSiCFe coated AISI 316 ASS.

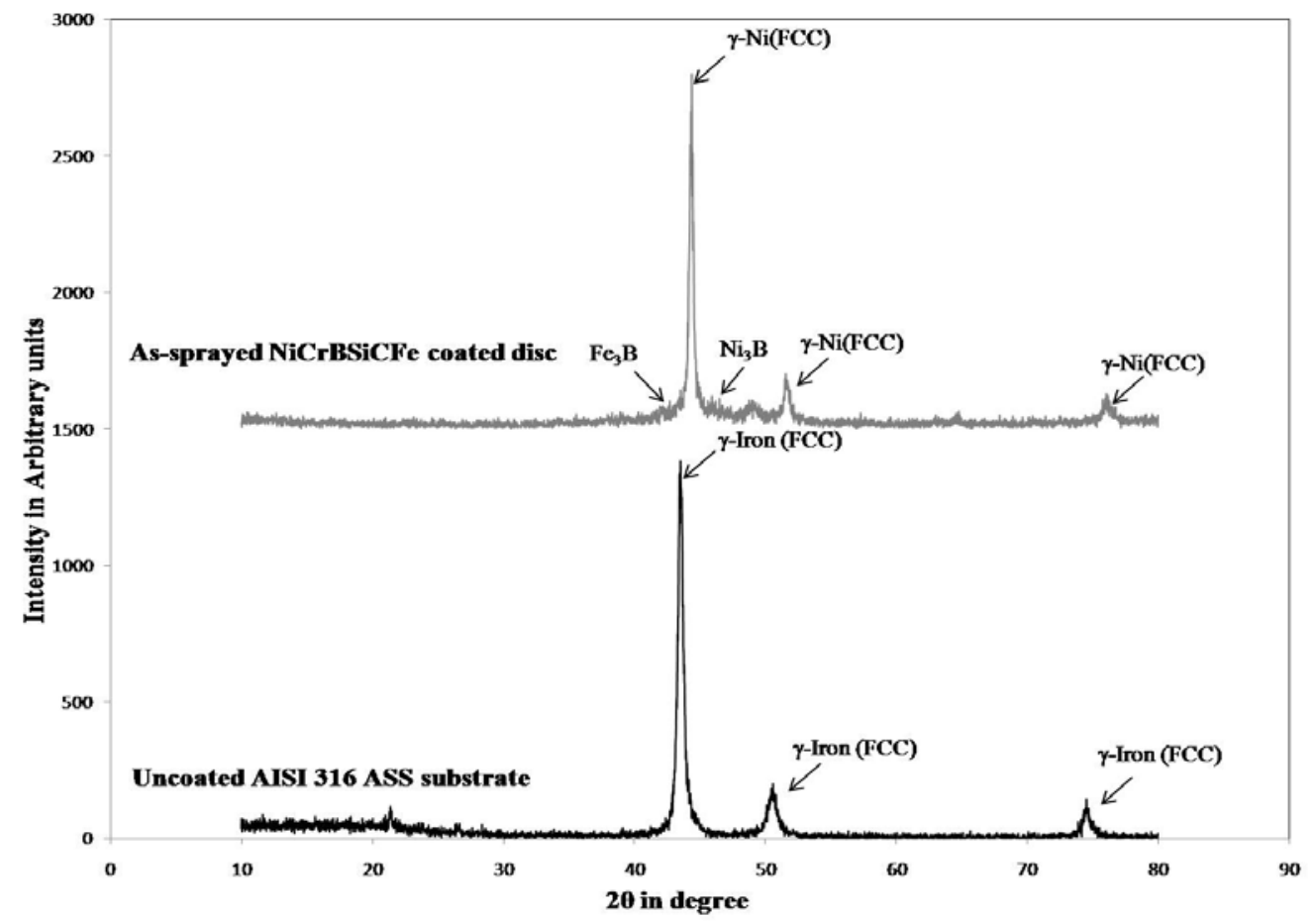

Figure 9. XRD pattern showing phases of uncoated and NiCrBSiCFe coated AISI 316 ASS substrates

\subsection{Worn Surface Characterisation by SEM}

Dry sliding leads to high local pressure between contacting asperities, which results in plastic deformation, adhesion and the consequent formation of junctions locally. The worn surface of the uncoated AISI 316 ASS substrates at room temperature is shown in Figure 10(a). Wear debris was sparsely present in the worn surface. The mode of material removal in room temperature was delamination. A grey dense plateau-like region was present in the worn surface of the uncoated AISI 316 ASS at $150^{\circ} \mathrm{C}$ is shown in Figure $10(\mathrm{~b})$. A cleavage was seen in the worn surface along with small amount of debris. The multilayered material removal exposing the subsurface for subsequent removal was seen in the SEM analysis. 
Figure 10(c) shows the worn surface of the uncoated AISI 316 ASS substrate. The deep prow justified the considerable amount of material loss during sliding. Subsurface was visible due to the subsequent removal of material. A comparatively deeper valley was noticed and it was due to the excess material removed by the sliding wear. The worn surface of the uncoated AISI $316 \mathrm{ASS}$ at $250^{\circ} \mathrm{C}$ is shown in Figure $10(\mathrm{c})$. Multilayered flake formations with more debris were prominently visible. These debris acts as an abrasive medium resulting in the excessive material removal during sliding [22]. Figure 10(d) shows the worn surface of the uncoated AISI $316 \mathrm{ASS}$ at $350^{\circ} \mathrm{C}$. The oxide formations which acted as a protective layer eliminated the chances of severe material loss. In contrast, the worn track formed by sliding wear of the coated samples had a very smooth and shiny appearance.

A distinct discipline in the mode of wear was attributed in the NiCrBSiCFe coated samples. The worn tracks were mostly characterized by score lines parallel to the sliding direction, which was sign of superior wear resistance. The surface morphology of NiCrBSiCFe coated specimen worn at room temperature is shown in Figure 11(a). The worn track exhibited microcracks with very few amount of scabs and debris. Plough markings were shown parallel to the sliding direction. As the time progresses, the delaminated layer may peel off and lead to considerable material loss. The worn surface morphology of the $\mathrm{NiCrBSiCFe}$ coated sample at $150^{\circ} \mathrm{C}$ is shown in Figure $11(\mathrm{~b})$. The mode of wear was found to be delamination with prow formation. Prow formation was just initiated at $150^{\circ} \mathrm{C}$. Scabs were sparsely seen eliminating the chances of more abrasive wear. The mode of material removal at $250^{\circ} \mathrm{C}$ was ploughing. The advanced stage in plough mode of material removal is prow formations. The deeper prow formations were the end result of frequent ploughings on the same instance. This mode leads to relatively more material loss which is evident from Figure 11(c).

The central core of a prow had undergone flattening and lateral spreading, which remains adherent to the base metal. The worn surface morphology of NiCrBSiCFe coated sample at $350^{\circ} \mathrm{C}$ is shown in Figure $11(\mathrm{~d})$. The initiation of oxide layer formation was visible in the SEM analysis. The score lines, which run always parallel to the sliding direction, were seen. The interesting phenomenon happened in the interface of the counterbody and the coated substrate is oxide formation. The oxide formation is visible in SEM. These oxide layers could be of $\mathrm{Fe}_{3} \mathrm{O}_{4}$ and $\mathrm{CrO}_{3}$. Oxide films formed during the contact play a protective part, eliminating the chances of excessive material loss. This lubrication property of the oxides reduced the severity of wear. Dry sliding wear leads to the removal of material from the surface by the formation of chips, shavings and fragments called debris. The geometry of the worn surface and a groove formed depends on the size and shape of the worn debris (abrasive particle). It was clearly noticed from the SEM observations that that the worn asperities seen on the worn surfaces of the coated surfaces are relatively finer, which was responsible for superior wear resistance [22]. 


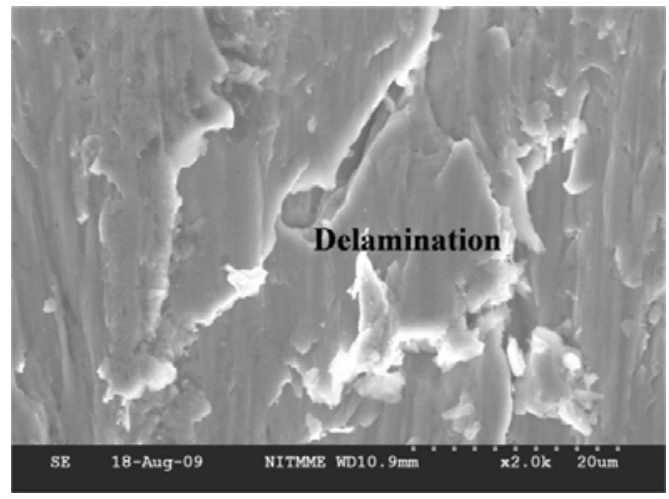

(a)

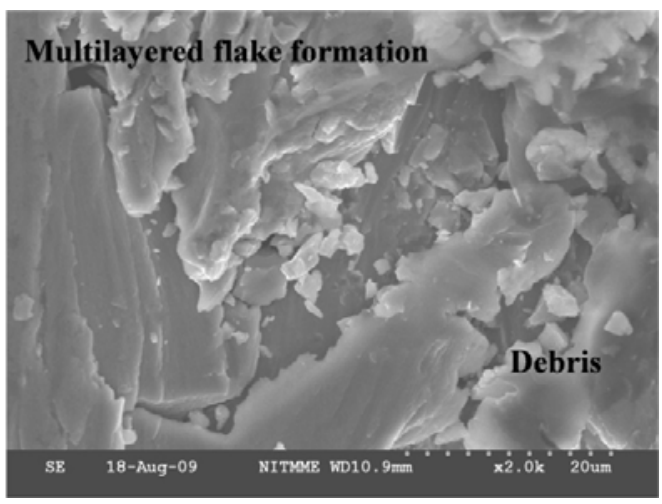

(c)

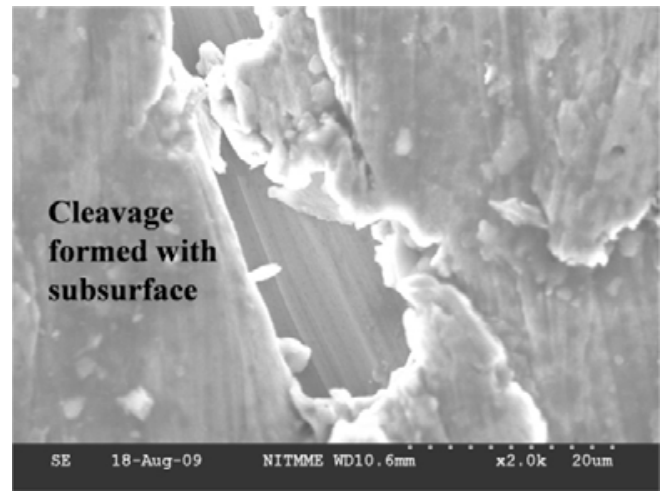

(b)

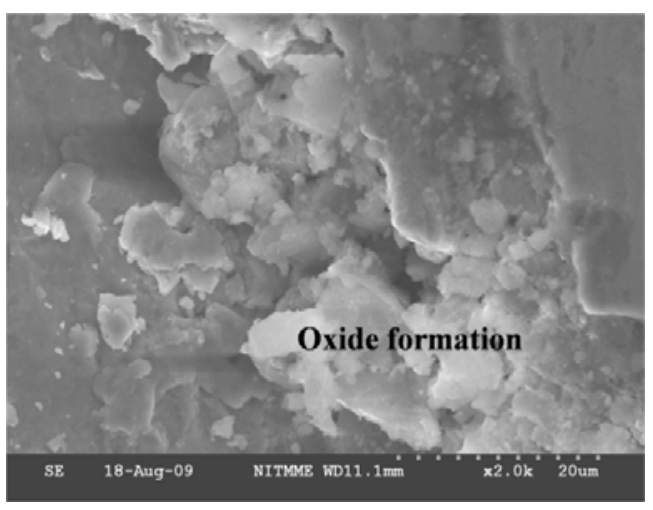

(d)

Figure 10. SEM picture of the uncoated AISI 316 ASS worn surfaces: (a) worn surface at room temperature (b) worn surface at $150^{\circ} \mathrm{C}$ (c) worn surface at $250^{\circ} \mathrm{C}$ (d) worn surface at $350^{\circ} \mathrm{C}$ 


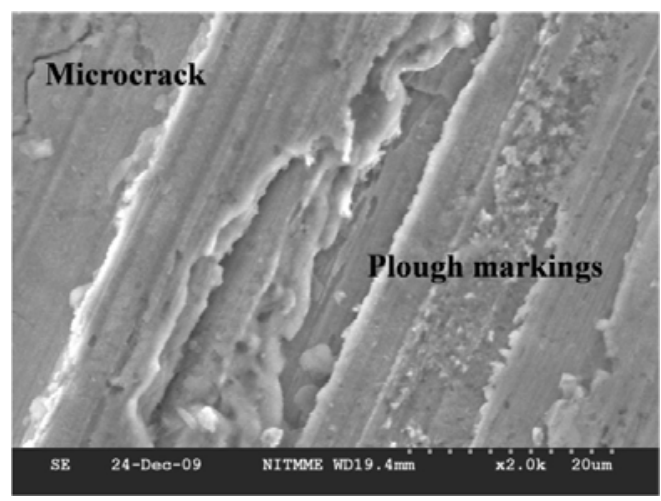

(a)

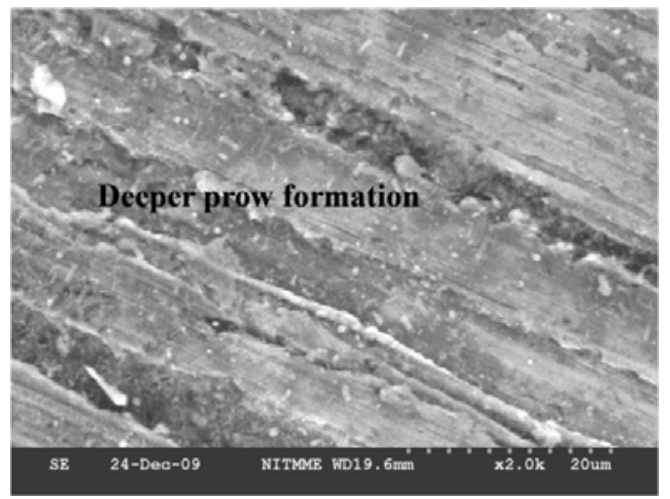

(c)

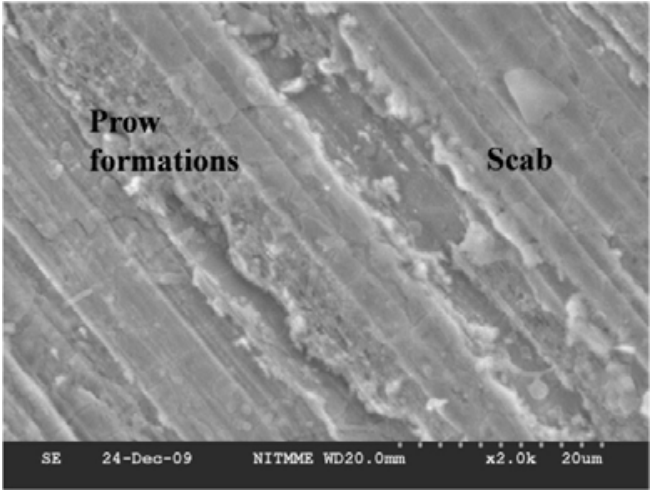

(b)

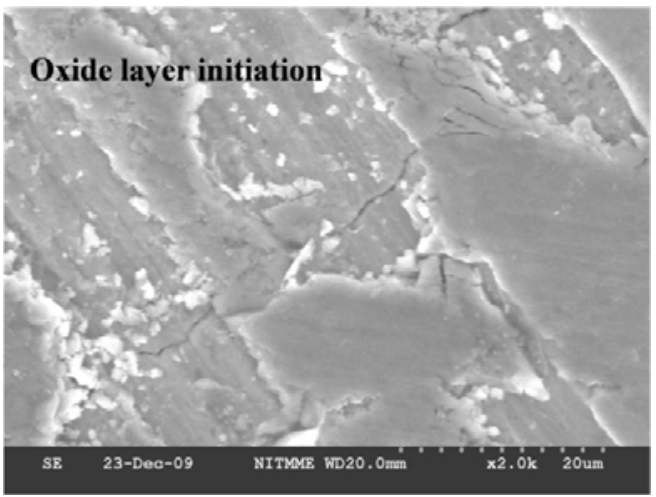

(d)

Figure 11. SEM picture of the NiCrBSiCFe coated surfaces: (a) worn surface at room temperature (b) worn surface at $150^{\circ} \mathrm{C}$ (c) worn surface at $250^{\circ} \mathrm{C}(\mathrm{d})$ worn surface at $350^{\circ} \mathrm{C}$

\section{CONCLUSIONS}

From the experiments conducted on uncoated and NiCrBSiCFe plasma sprayed AISI 316 ASS substrates at various operating temperatures, the following conclusions can be drawn.

- The NiCrBSiCFe was plasma sprayed on AISI 316 ASS to a thickness of up to 500 $\mu \mathrm{m}$. The coatings produced were physically bonded to the substrate and free from porosity.

- The improvement in hardness up to an average value of $822 \mathrm{HV}_{0.3}$ of AISI 316 ASS from $223 \mathrm{HV}_{0.3}$ was achieved by $\mathrm{NiCrBSiCFe}$ plasma spraying primarily contributed to the improvement of wear resistance.

- The plasma sprayed NiCrBSiCFe coating exhibited up to 4.5 times increase in wear resistance compared to the uncoated AISI 316 ASS substrates. 
- The superior wear resistance of the NiCrBSiCFe coated samples in the operating temperature $350^{\circ} \mathrm{C}$ justifies the applicability of the coating for high temperature applications involving sliding contact.

- The molten splats formed during plasma spraying leading to the lamellar microstructure were responsible for the higher hardness and higher wear resistance in coated AISI 316 ASS substrates.

- The worn surface morphology analysed by SEM revealed the presence of oxide formations at $350^{\circ} \mathrm{C}$. This was a minimal material removing mode which excluded the chance of more material loss.

- The SEM analysis of the worn tracks concluded that more plastic deformation and material loss had been incurred by the uncoated substrates than the NiCrBSiCFe plasma sprayed AISI 316 ASS.

- The geometry of the worn asperities of the NiCrBSiCFe plasma spayed coating was finer compared to the uncoated specimens. This property reduced the intensity of wear rate in coated specimens. The SEM results were found to be in accordance with the sliding wear test results.

\section{REFERENCES}

[1] Whittle R.D., Scott V.D., 1984, "Sliding-wear evaluation of nitrided austenitic alloys", Met. Technology, 11(6), 231-241 .

[2] Smith A.F., 1986, "Influence of environment on the unlubricated wear of 316 stainless steel at room temperature", Tribol. Int., 19, 1-10

[3] Tarassov, S.Yu., Kolubaev, A.V.,1999, "Effect of friction on subsurface layer microstructure in austenitic and martensitic steels", Wear, 231, 228-234.

[4] Betancourt-Dougherty L.C., Smith R.W., 1998, "Effects of load and sliding speed on the wear behaviour of plasma sprayed TiC-NiCrBSi coatings", Wear, 217 147-154.

[5] Belzunce F.J., Higuera V., Poveda S., and Carriles A., 2002, "High Temperature Oxidation of HFPD Thermal-Sprayed MCrAlY Coatings in Simulated Gas Turbine Environments", J. Therm. Spray Technol., 11(4), 461-467.

[6] Sun Y., Bell T., 2002, "Effect of layer thickness on the rolling-sliding wear behavior of low temperature plasma-carburized austenitic stainless steel", Tribol. Lett., 13, 1, 29-34. [7] Straffelini, G, Trabucco, D., and Molinari, A., 2002, "Sliding Wear of Austenitic and Austenitic-Ferritic Stainless Steels”, Metall. Mater. Trans. A, 33A, 613-624.

[8] Sun Y., Bell T., 2002, "Dry sliding wear resistance of low temperature plasma carburised austenitic stainless steel", Wear, 253, 689-693.

[9] Fleury E., Kim Y.C., Kim J.S., Kim D.H., Kim W.T., Ahn H.S and Lee S.M., 2002, "Tribological properties of $\mathrm{Al}-\mathrm{Ni}-\mathrm{Co}-\mathrm{Si}$ quasicrystalline coatings against $\mathrm{Cr}$-coated cast iron disc", J. Alloys Compd., 342, 321-325.

[10] Higuera V., Belzunce F. J., Carriles A., Poveda S., "Influence of the thermal-spray procedure on the properties of a nickel-chromium coating", J. Mater. Sci., 372002 649-654 
[11] Pershin V., Lufitha M., Chandra S., and Mostaghimi J., 2003, "Effect of Substrate Temperature on Adhesion Strength of Plasma-Sprayed Nickel Coatings", J. Therm. Spray Technol., 12(3), 370-376

[12] Bregliozzi G., Ahmed S.I.-U., Di Schino A., Kenny J.M., and Haefke H., 2004, "Friction and wear behavior of austenitic stainless steel: influence of atmospheric humidity, load range, and grain size", Tribol. Lett., 17, 4, 697-704.

[13] Sidhu T. S., Prakash S., and Agrawal R. D., 2005, "Studies on the properties of highvelocity oxy-fuel thermal spray coatings for higher temperature applications", Materials Science, 41, 6, 805-823.

[14] Navas C., Vijande R., Cuetos J.M., Fernández M.R., Damborene J. de., 2006, Corrosion behaviour of NiCrBSi plasma-sprayed coatings partially melted with laser, Surf. Coat.

Technol,. 201, 776-785.

[15] Hai-dou Wang, Bin-shi Xu, Jia-jun Liu, Da-ming Zhuang, Shi-cheng Wei, Guo Jin, 2007, "The iron sulfide coatings prepared by plasma spraying and their friction-reduction performance", Surf. Coat. Technol., 201, 5286-5289.

[16] Harsha S., Dwivedi D.K., and Agarwal A., 2008, "Performance of Flame Sprayed NiWC Coating under Abrasive Wear Conditions”, J. Mater. Eng. Perform., 17(1), 104-110. [17] Budzynski P., Polanski K., Kobzev A. P., 2008, "Changes in Surface Properties of Nitrogen-Implanted AISI316L Stainless Steel”, J. Surf. Invest., 2, 4, 657-662.

[18] Manoj Singla, Lakhvir Singh, Vikas Chawla, 2009, "Study of Wear Properties of Al-SiC Composites", J. Min. Mat. Charct. Engg., 8, 10, 813-819.

[19] Nascimento F. C., Lepienski C. M., Foerster C. E., Assmann A.,. da Silva S. L. R., Siqueira C. J. de M., Chinelatto A. L., 2009, "Structural, mechanical, and tribological properties of AISI 304 and AISI 316L steels submitted to nitrogen-carbon glow discharge", J. Mater. Sci., 44, 1045-1053.

[20]Shenglin Liu , Xueping Zheng, Gangqiang Geng, 2010, "Dry sliding wear behavior and corrosion resistance of NiCrBSi coating deposited by activated combustion-high velocity air fuel spray process", Mater. Des., 31, 913-917.

[21] ASTM G99-95, 1995. ASTM G99-95a (reapproved 2000): standard test method for wear testing with a pin on disk apparatus.

[22] Hutchings I. M, 1992, Tribology, Friction and wear of engineering materials, Butterwort-Heinemann. 